\title{
Review of philopatry and its strategy in xeric environments
}

\author{
Eduardo Felipe Aguilera-Miller ${ }^{1}$ and Sergio Ticul Álvarez-Castañeda ${ }^{2 *}$. \\ ${ }^{1}$ Laboratorio de la Estación Científica La Malinche, Centro Tlaxcala de Biología de la Conducta, Universidad Autónoma de Tlaxcala. \\ Km 1.5 Carretera Tlaxcala-Puebla S/N, CP. 90070, Tlaxcala. Tlaxcala, México. Email: aguileramiller.ed@gmail.com (EFA-M) \\ ${ }^{2}$ Centro de Investigaciones Biológicas del Noroeste S. C. Instituto Politécnico Nacional 195, CP. 23096, La Paz. Baja California Sur, \\ México. Email: sticul@cibnor.mx (STAC). \\ ${ }^{*}$ Corresponding author
}

\begin{abstract}
Over recent decades, dispersal and philopatry in natural populations have been addressed together. However, philopatry, or the tendency of an individual to remain in its birthplace, has received little attention, despite the fact that this trait is present in a considerable number of vertebrates. In this paper we discuss hypotheses that state philopatry generators: life-history variables, ecological constraints, benefits of philopatry and agonistic behaviors. Additionally, we propose that genetic microstructure may be an outcome of such behavior. We conducted an analysis based on the above hypotheses in order to explain the presence of philopatry in rodents of arid environments.

En las últimas décadas, la dispersión y la filopatría han sido abordadas en conjunto. La filopatría o la tendencia de un individuo a permanecer en su lugar de nacimiento, es un comportamiento ampliamente observado entre los vertebrados. Aún así, tal comportamiento ha recibido poca atención. En este trabajo, se discuten hipótesis como las variables en las historias de vida, las restricciones ecológicas, los beneficios de la filopatría y los comportamientos agonísticos como generadores del comportamiento filopátrico. Adicionalmente se propone que la microestructura genética puede ser resultado de tal comportamiento. Realizamos un análisis basado en las hipótesis previas para explicar la presencia de filopatría en roedores de ambientes áridos.
\end{abstract}

Keywords: aggressive behavior; desert rodents; dispersal; ecological constraints; genetic microstructure; life-history traits.

(C) 2019 Asociación Mexicana de Mastozoología, www.mastozoologiamexicana.org

\section{Introduction}

Philopatry is a behavioral trait present in a wide variety of animal populations, principally mammals (Waser and Jones 1983), birds (Welty and Baptista 1988), reptiles (Meylan et al. 1990), and fish (Gold et al. 1999). Philopatry has been conceived of in different ways depending on the author and the group of organisms studied. The most generalized interpretations refer to an individual's tendency to remain in (mammals), or return to its birthplace (birds, reptiles, and fish). Owing to its various connotations, we will use the idea described by Waser and Jones (1983), which refers to the behavior of an individual remaining in its birthplace even after having reached maturity and independence from progenitors.

Particular patterns of this behavior include natal and sex-specific philopatry (Hueter et al. 2005). Natal philopatry, or retention of offspring within parental territory, once past the age of dependence from parents, is common among species (Greenwood 1980; Perrin and Lehmann 2001) because it ensures access to shelter and food sites, among others. Moreover, it is considered of central importance as a method to conform and extend relationships among individuals that share recent ancestry (Matocq and Lacey 2003), which is a prerequisite of many common phenomena in gregarious species (Holekamp et al. 2012).

Philopatry is also present in solitary species. It is necessary to mention that the fact that individuals of certain species are considered as solitary does not mean that such individuals are not social. The conditions that have led to the emergence of philopatry in vertebrates are an impor- tant factor to understand how complex social groups have evolved (Lacey and Ebensperger 2007).

Most philopatric patterns exhibit sex bias. Such patterns may be related to the mating system of each species itself. The hypothesis of resource defense (Greenwood 1980) proposes that the philopatric sex-males in birds and female in mammals - is the one that most benefits from being familiar with the area where it lives. The sex less involved in the acquisition of resources should be the one that present dispersal (Lawson-Handley and Perrin 2007). A common feature in species with philopatric males is their defense of any important resource critical for acquiring mates for breeding. Successful competition among males for females lies in their ability to maintain the resource, rather than defend females (Greenwood 1980). In species with philopatric females, a widespread characteristic is the need to have access to a resource that allows the female to rear the offspring. Thus, females form stable nuclei and males adopt strategies to maximize their access to these groups (Schradin and Lindholm 2011). Males do not invest much in their progeny and benefit from dispersal, while females invest significant effort in their progeny and benefit from philopatry (Lawson-Handley and Perrin 2007; Vázquez and Álvarez-Castañeda 2014). The outstanding plasticity of the mating systems recorded among natural populations, have led to a variety of ideas around such topic. On the other hand, the general idea is that polygyny is the common mating system observed in mammals. Nevertheless, since a great amount of studies have focused on males, the female perspective has often been ignored, resulting in a lack of 
information about the mating systems present in mammals (Shuster and Wade 2003; McEachern et al. 2009).

Philopatry has been studied from different angles. Possibly the one most discussed is that of dispersal, which is understood as the "antipodal" of philopatry. In many vertebrates, juveniles leave home before reaching sexual maturity and move significant distances before settling as breeding individuals (Waser and Jones 1983). Selection should favor these individuals for several reasons. Among other benefits for those who dispersal are a higher frequency of encounters with individuals of the opposite sex, the rearing of a genetically variable brood, and access to free habitats. But what happens to the species in which individuals remain all their lives within the parental home? Inevitably, their philopatric status has an evolutionary reason that has benefited them over time.

An emerging point of view considers that philopatry is influenced by the advantages that an individual has when it remains in a known or familiar habitat, without having to experience the disadvantages of dispersal, such as the risk of being preyed upon or not finding available territory (Solomon 2003; van Noordwijk et al. 2012). Within this conceptual framework, several elements have been addressed as causing philopatry. Those that have received most attention are: variables in life-histories (Kokko and Lundberg 2001; Solomon 2003), ecological constraints (Solomon 2003; Schradin et al. 2010), and benefits of philopatry (Kokko and Johnstone 1999; Solomon 2003).

\section{Variables in life-history traits}

Different studies (Krause and Ruxton 2002) have proposed models that allow the presence of philopatry in species with altricial or slowly developing offspring to be predicted. It is possible that individuals of these species must delay natal dispersal, because they need more parental care in order to survive before reaching adulthood (Blumstein and Armitage 1999). One fact that may support this hypothesis is that the dispersal of individuals is delayed until they have the ability to contend for the resources that are critical for reproduction, such as mates, breeding sites, or food. The longevity of the individuals is another important factor and has been linked to restricted space or habitat saturation. Kokko and Lundberg (2001) suggest that habitat saturation is not the primary factor causing philopatry, but rather the longevity or lifespan of members of the population, which will define the occupation of vacant sites and the recruitment of new breeding individuals into the group.

\section{Ecological constraints}

Although philopatry has evolved in species over a long period of time, there are different ways in which the behavior of a species can be affected by the environment. Differences in habitat quality will guide individuals of natural populations to present dispersal or remain philopatric. If optimal habitats are saturated or limited, the answer is the philopatry, which somehow ensures the provision of critical resources such as food or safe nesting sites. Once vacant sites are avail- able, dispersal will be possible (Schradin et al. 2010), with the subsequent relaxing of the philopatric response.

Ecological constraints also involve some risk during dispersal, such as that of predation. In this case, an individual stays longer in a suboptimal and no well-known habitat, unlike that encountered were it to stay in its place of origin. Moreover, the need to find available food in unknown sites makes it particularly susceptible to predation.

Additionally, it has been proposed that arid environments promote the formation of groups of individuals and favor philopatry (Solomon 2003; Sichilima et al. 2008). This hypothesis states that extreme conditions, unpredictable and sporadic rainfall, and the pattern of food resource distribution in such environments may impose severe restrictions on dispersal. Because of this, individuals are forced to stay in their birth area, leading to philopatry and the formation of family groups. It has been documented that after a period of considerable precipitation, both activity and foraging area increase in desert species, which is proposed as an indication of dispersal (Lacey and Wieczorek 2003).

\section{Benefits of philopatry}

The benefits of philopatry may be direct or indirect. The direct benefits influence the survival and reproduction of only a single individual. In contrast, the indirect benefits affect the survival and reproduction of offspring or, in a broader sense, the general population. The inheritance of territory is a potential benefit to philopatric populations. Although little is known about optimal territory inheritance (McGuire et al. 1993), this hypothesis is interesting, as by staying in its home area an individual is subject to inheriting a high quality territory; in addition, it will not need to present dispersal in order to find space. Thus, over time, well-established genealogical groups will form (Randall and Stevens 1987). One additional advantage of living close to the family is increased tolerance among individuals, thus avoiding clashes and attacks that can have a high cost during times of intense competition for resources (Holekamp et al. 2012). Group cooperation in obtaining food, in defending refuge and breeding sites, and in caring for offspring are some examples of the ways in which philopatry and the formation of kinship groups benefit different species (Blumstein and Armitage 1999; Lacey and Sherman 2007).

\section{Philopatry in arid environments}

A successful way to study mammal behavior has been the comparison of different patterns among closely related species (Randall 1993; Meshriy et al. 2011). As examples, studies among squirrels (Sciuridae) can be cited. These have helped researchers in developing behavioral models to explain the evolution of social organizations, mating systems, and the presence of philopatry in this taxon (Michener 1983); another example is mole rats (Bathyergidae). This group presents very complex social characteristics ranging from extremely solitary and aggressive species to possibly the most-studied social mammal, the naked mole rat Heterocephalus glaber (Jarvis and Bennett 1991; Sichilima et al. 2008). 
Rodents of the Heteromyidae (kangaroo rats and pocket mice) are another group of mammals for whom comparative studies have yielded a great deal of information about the evolution of different behavior patterns, including philopatry. The heteromyids differ from other mammals by being nocturnal inhabitants of North American arid environments, and communities can be very complex (Vaughan et al. 2000). Their presence in open habitats, their rapid familiarization with human observers, and their philopatric tendency are characteristics that make them ideal for behavioral studies in situ (Randall 1984). Another advantage of studying the behavior of heteromyids is their rapid adaptation to captivity. Laboratory experiments with controlled variables make it possible to test different hypotheses based on field observations.

The main behavioral studies on desert heteromyids have focused on the kangaroo rat (Dipodomys spp., Randall 1984; Cooper and Randall 2007; Meshriy et al. 2011), while for other genera (Perognathus, Microdipodops and Chaetodipus) there is a significant lack of information. Heteromyids are mainly granivorous and live in environments where extreme precipitation cycles alternate with long periods of drought. Because of this, they carry food to their burrows to hoard and subsequently consume. It has been documented that during times of extreme temperatures, pocket mice can enter a state of torpor, using 20 to 30 percent of their energy - unlike kangaroo rats who do not have this capability-so they depend on the accumulated reserves in their burrows to maintain normal energy requirements (MacMillen 1983). This hoarding of food as well as locating safe places for shelter allow them to survive periods of scarcity or extreme environmental conditions (Vander Wall 1990), benefits accrued from their philopatric nature.

Authors such as Randall (1993), have proposed that evolution has favored the clustering of groups of individuals to confront the risk of being preyed upon in open or scarcely vegetated areas. Nevertheless, heteromyids are mostly solitary and cannot rely on the protection of a group. Instead, solitary species depend on morphological strategies such as cryptic coloration and special behaviors (Mares 1983). The heteromyids may be particularly vulnerable to predation during social interactions, since their attention is focused on conspecifics. Such is the case of the kangaroo rat, which devotes considerable time to mating, defending territories, and dispersal. This is how, by maintaining a stable social environment and familiarity with the area it inhabits, an individual can successfully avoid predation (Daly et al. 1990).

Although the heteromyids are a group of solitary species, these rodents have established solid social systems and have developed familiarity with closely related individuals (Cooper and Randall 2007). Both males and females reproduce and raise offspring in their home territories, a pattern that imposes significant restrictions on dispersal and promotes connections among individuals (Jones 1989). In addition, the overlapping of individuals' territories is a common phenomenon that contributes to the spatial and social organization of populations (Vázquez and Álvarez-Castañeda 2014). Furthermore, the relatively long lifespan (1 year to a maximum of 4-6 years, depending on the species) and the fact of remaining in the same burrow over this time, also promote long-term relationships among neighbor individuals. Among D. spectabilis females, burrows are shared and even passed on from mothers to daughters (Waser 1988; Vázquez and Álvarez-Castañeda 2014). It has been documented that kangaroo rat juveniles that inherit parental burrows are more likely to survive to reproductive age than individuals who have presented dispersal (Jones 1986).

The kangaroo rat shows high activity around its burrow because it maintains constant interaction with other rodents (Leaver and Daly 2001). The coexistence of up to six different species, including Dipodomys spp., has been documented on deserts (Vaughan et al. 2000), which confirms that the defense of burrows between conspecifics and sympatric species is a generalized pattern.

Genetic microstructure studies have shown that there is a wide variety of haplotypes with very restricted distribution in species of the genus Chaetodipus. Derived haplotypes are found in optimal habitats, while ancestral ones are found in less optimal ones (s. s. Banks 1964; AguileraMiller et al. 2018b). These findings led to a study of agonistic behaviors that recorded intense aggression among females, which have the tendency to monopolize food resources and space (Aguilera-Miller et al. 2018a). The defense of such resources may be more important among females because they are the sex that requires more energy to maintain costly reproductive activities (Vázquez and Álvarez-Castañeda 2014).

The combination of a clear genetic microstructure and strong female aggression when defending food resources from other individuals regardless of sex indicates marked territoriality. This territoriality is reflected in the control of an area to rear the young (Wolff and Peterson 1998) or to pass it on to their offspring, creating strong philopatry. These results may be related to observations made in other species such as D. merriami and D. heermanni, in which there is minimal territory overlapping among females (Jones 1989); thus we can infer that low tolerance among females is possibly a widespread pattern in heteromyids.

The fact that unique matrilineal haplotypes occur in areas only $1.7 \mathrm{~km}$ apart may indicate little dispersal of females between sites (Aguilera-Miller et al. 2018b). Similar results were documented in populations of the desert cricetid Neotoma micropus; private matrilineal haplotypes were found among sites separated by $2 \mathrm{~km}$, which suggests a limited effective dispersal among subpopulations (Méndez-Harclerode et al. 2005). The geographic restriction of haplotypes with clear spatial segregation may be rooted in the philopatric character of the females (Aguilera-Miller et al. 2018b).

For philopatry to be considered an evolutionary advantage, the fitness of philopatric species must be proven. In species where females remain philopatric, the formation of family groups is common. Associating in groups will 
promote breeding success and survival (Silk 2007) as well as cooperation in obtaining food and defending breeding sites (Silk 2007). In species with slow maturation rates, philopatry offers an advantage, because if parents remain philopatric, this somehow assures their access to resources needed to feed the young (Blumstein and Armitage 1999). When there are adverse conditions and food is not assured, some species choose philopatry, avoiding dispersal.

For over thirty years efforts have been made to explain the presence and evolutionary significance of philopatry among different species of vertebrates. These studies have been relevant to different areas of biology such as demography, population genetics, and behavioral ecology (Clutton-Brock and Lukas 2012). As we have seen, they have resulted in numerous definitions, which have led to confusing comparisons and complicated conclusions; to this day, little agreement remains as to the importance of the different evolutionary mechanisms that have caused philopatry (Greenwood 1980; Ronce 2007; Clobert et al. 2008).

Although the assumptions discussed above differ in importance according to the species in question, it has been proposed that they be unified in a generalized model that can theoretically explain the presence of philopatry in natural populations (Solomon 2003; Doerr and Doerr 2006). To better understand the mechanism of action of the factors involved in philopatry, it is necessary to consider two general ideas. The first has to do with the consistent presence of philopatry in a certain species. In this case, variables in life-history traits are the guiding factors for the existence of this trait. The second idea is related to species in which philopatry occurs when certain ecological conditions do not favor dispersal. An example of this type are the mole rats (Bathyergidae) inhabiting arid regions of Africa. There is a relationship between the distribution of the rats and patches of geophytes, their main source of food. The behavior of these populations is gregarious. In contrast, solitary populations live in mesic environments where their food source is more evenly distributed and, hence, more easily found by individuals who disperse separately (Sichilima et al. 2008). Although social populations can be found in both habitats, solitary ones are not present in arid environments. It would be useful to determine whether competition for reproduction among individuals of the same sex increases, or whether groups tend to dissolve when they reach a certain size or composition, owing to the change in conditions that lead to philopatry.

It is possible to conclude that philopatry is a response to the interaction of a number of ecological and biological variables that threaten the reproductive success of individuals. The questions that arise are mainly related to the fact that since each species has very special ecological requirements, as well as a different life history, it benefits from philopatry in a unique way. Many questions remain and much remains to be done to understand the phenomenon of philopatry.

\section{Acknowledgments}

We are thankful to Carmen Izmene Gutiérrez Rojas and Andrea Campos Rubio for their valuable help in the agonistic behavior experiment; the Centro de Investigaciones Biológicas del Noroeste S. C. for the facilities provided; and the Consejo Nacional de Ciencia et al Tecnología for the funds provided for project 151189 to cover costs of the experiments.

\section{Literature cited}

Aguilera-Miller, E. F., B. K. Lim, R. W. Murphy, and S. T. ÁlvarezCASTAÑEDA. 2018a. Dominance by extremely high aggressive behaviors in relation to genetic microstructure in matrilines. Mammalian Biology 89:1-6.

Aguilera-Miller, E. F., S. T. Álvarez-Castañeda, and R. W. Murphy. 2018b. Matrilineal genealogies suggest very low dispersal in desert rodent females. Journal of Arid Environments 152:28-36.

BAnks, R. C. 1964. The mammals of Cerralvo island, Baja California. Transactions of the San Diego Society of Natural History 13:397-404.

Blumstein, D. T., AND K. B. Armitage. 1999. Cooperative breeding in marmots. Oikos 84:369-382.

Clobert, J., M. De Fraipont and E. Danchin. 2008. Behavioural ecology. Pp. 323-359 in Behavioural Ecology (Danchin, E, L. A. Giraldeau, and F. Cezilly, eds.). Oxford University Press. Oxford, U.K.

Clutton-Brock, T. H., AND D. LuKAs. 2012. The evolution of social philopatry and dispersal in female mammals. Molecular Ecology 21:472-492.

Cooper, L. D., AND J. A. RANDAll. 2007. Seasonal changes in the home ranges of the giant kangaroo rat (Dipodomys ingens): a study of flexible social structure. Journal of Mammalogy 88:1000-1008.

Daly, M., M. I., Wilson, P. R., Behrends, and L. F. Jacobs. 1990. Characteristics of kangaroo rats, Dipodomys merriami, associated with differential predation risk. Animal Behaviour 40:380-389.

DoerR, E. D., AND V. A. J. Doerr. 2006. Comparative demography of treecreepers: evaluating hypotheses for the evolution and maintenance of cooperative breeding. Animal Behaviour 72:147-159.

Gold, J. R., L. R. RiChardson, AND T. F. TuRner. 1999. Temporal stability and spatial divergence of mitocondrial DNA haplotype frequencies in red drum (Sciaenops ocellatus) from coastal regions of the western Atlantic Ocean and Gulf of Mexico. Marine Biology 133:593-602.

Greenwood, P. J. 1980. Mating systems, philopatry and dispersal in birds and mammals. Animal Behaviour 28:1140-1162.

Holekamp, K. E., J. E. Smith, C. C.Strelioff, R. C. Van Horn, and H. E. WATTS. 2012. Society, demography and genetic structure in the spotted hyena. Molecular Ecology 21:613-632.

Jarvis, J. U. M., AND N. C. BennetT. 1991. Ecology and behavior of the family Bathyergidae. Pp. 66-96 in The Biology of the Naked Mole-rat (Sherman, P. W., J. U. M. Jarvis, and R. D. Alexander, eds.). Princeton University Press. New Jersey, U. S. A.

JONES, W. T. 1986. Survivorship in philopatric and dispersing kangaroo rats (Dipodomyis spectabilis). Ecology 67:202-207. 
JONES, W. T. 1989. Dispersal distance and the range of nightly movements in Merriam's kangaroo rats. Journal of Mammalogy 70:27-34.

KокKo, H., AND R. A. Johnstone. 1999. Social queuing in animal societies: a dynamic model of reproductive skew. Proceedings of the Royal Society of London. Series B, Biological Sciences 266:571-578.

KokKo, H., And P. Lundberg. 2001. Dispersal, migration, and offspring retention in saturated habitats. The American Naturalist 157:188-2002.

Krause, J. and G. D. Ruxton. 2002. Living in groups. Oxford University Press. Oxford, U.K.

LACEY, E. A., AND J. R.WieCzOREK. 2003. The ecology of sociality in rodents: a ctenomyid perspective. Journal of Mammalogy 84:1198-1211.

Lacey, E. A. And L. A. Ebensperger. 2007. Social structure in octodonid and ctenomyid rodents. Pp. 403-415 in Rodent Societies: An Ecological and Evolutionary Perspective (Wolff, J.O. and P. W. Sherman, eds.) Chicago University Press. Chicago, U.S. A.

Lacey, E. A., And P. W. Sherman. 2007. The ecology of sociality in rodents. Pp. 243-254 in Rodent Societies: An Ecological and Evolutionary Perspective (Wolff, J.O. and P. W. Sherman, eds.) Chicago University Press. Chicago, U.S. A.

Lawson-Handley, L. J., And N. Perrin. 2007. Advances in our understanding of mammalian sex-biased dispersal. Molecular Ecology 16:1559-1578.

Leaver, L. A., AND M. Daly. 2001. Food caching and differential cache pilferage: a field study of coexistence of sympatric kangaroo rats and pocket mice. Oecologia 128:577-584.

MacMillen, R. E. 1983. Adaptive physiology of heteromyid rodents. Great Basin Naturalist Memoirs 7:65-75.

MARES, M. A. 1983. Desert rodent adaptation and community structure. Great Basin Naturalist Memoirs 7:30-43.

MatocQ, M. D., AND E .A. LACEY. 2003. Philopatry, kin clusters, and genetic relatedness in a population of woodrats (Neotoma macrotis). Behavioral Ecology 4:647-653.

McGuire, B., L. L. Getz, J. E. Hofmann, T. Pizzuto, and B. Frase. 1993. Natal dispersal and philopatry in prairie voles (Microtus ochrogaster) in relation to population density, season, and natal social environment. Behavioral Ecology and Sociobiology 32:293-302.

Méndez-Harclerode, F. M., J. D. Hanson, C. F. Fulhorst , M. L. Milazzo, D. C. Ruthven III, and R. D. Bradley. 2005. Genetic diversity within the southern plains woodrat (Neotoma micropus) in southern Texas. Journal of Mammalogy 86:180-190.

Meshriy, M. G., J. A. Randall and L. ParRa. 2011. Kinship associations of a solitary rodent, Dipodomys ingens, at fluctuating population densities. Animal Behaviour 82:643-650.

Meylan, A., B. W. Bowen, and J. C. Avise. 1990. A genetic test of the natal homing versus social facilitation models for green turtle migration. Science 248:724-727.

McEachern, M. B., R. L. McElreath, D. H. Van Vuren, and J. M. EADIE. 2009. Another genetically promiscuous 'polygynous' mammal: mating system variation in Neotoma fuscipes. Animal Behaviour 77:449-455.

Michener, G. R. 1983. Kin identification, matriarchies and the evolution of sociality in ground-dwelling sciurids. Pp. 528-572 in Advances in the Study of Mammalian Behavior
(Eisenberg, J. F., and D. G. Kleiman, eds.). Special Publication No. 7. The American Society of Mammalogists.

Perrin, N., And L. Lehmann. 2001. Is sociality driven by the costs of dispersal or the benefits of philopatry? A role for kin-discrimination mechanisms. American Naturalist 158:471-483.

RandalL, J. A. 1984. Mating strategies of a nocturnal desert rodent (Dipodomys spectabilis). Behavioral Ecology and Sociobiology 28:215-220.

RANDALL, J. A. 1993. Behavioural adaptations of desert rodents (Heteromyidae). Animal Behaviour 45:263-287.

Randall, J. A., and C. M. Stevens. 1987. Footdrumming and other anti-predator responses in the bannertail kangaroo rat (Dipodomys spectabilis). Behavioral Ecology and Sociobiology 20:187-194.

Ronce, O. 2007. How does it feel to be a rolling stone? Ten questions about dispersal evolution. Annual Review of Ecology Evolution and Systematics 38:231-253.

Schradin, C., B. König, and N. Pillay. 2010. Reproductive competition favours solitary living while ecological constraints impose group-living in African striped mice. Journal of Animal Ecology 79:515-521.

SChradin, C. N., AND A. K. Lindholm. 2011. Relative fitness of alternative male reproductive tactics in a mammal varies between years. Journal of Animal Ecology 80:908-917.

Shuster, S. M., And M. J. Wade. 2003. Mating systems and strategies. Princeton University Press. New Jersey, U. S. A.

Sichilima, A. M., N. C. Bennett, C. G. Faulkes, and S. C. Le Comber. 2008. Evolution of African mole-rat sociality: burrow architecture, rainfall and foraging in colonies of the cooperatively breeding Fukomys mechowii. Journal of Zoology 275:276-282.

SILK, J. B. 2007. The adaptive value of sociality in mammalian groups. Philosophical transactions of the Royal Society of London. Series B, Biological Sciences 362:539-559.

Solomon, N. G. 2003. A reexamination of factors influencing philopatry in rodents. Journal of Mammalogy 84:1182-1197. van Noordwijk, M. A., N. Arora, E. P. Willems, L. P. Dunkel, N. A. Rahmalia, N, Mardianah, C. Ackermann, M. Krützen, and C. P. van SCHAIK. 2012. Female philopatry and its social benefits among Bornean orangutans. Behavioral Ecology and Sociobiology 66:823-834.

Vander Wall, S. B. 1990. Food Hoarding in Animals. University of Chicago Press. Chicago, U. S. A.

Vaughan, T. A., J. A. Ryan, And N. J. CZaplewski. 2000. Mammalogy, $4^{\text {th }}$ edition. Saunders College Publishing. Fort Worth, U. S. A.

Vázquez, P. J., and S. T. Álvarez-Castañeda. 2014. Influence of kangaroo rat burrows in the spatial organization of the San Jose Island rodent community. Journal of Arid Environments 111:84-90.

WASER, P. M., AND W.T. JONES. 1983. Natal philopatry among solitary mammals. The Quarterly Review of Biology 58:355-390.

WASER, P. M. 1988. Resources, philopatry, and social interactions among mammals. Pp. 109-130 in The ecology of social behavior (Slobodchikoff, C. N. ed.). Academic Press San Diego, U. S. A.

Welty, J. C., and L. Baptista. 1988. The life of birds. Saunders College Publishing. New York, U. S. A. 
WolfF, J. O., AND J. A. Peterson. 1998. An offspring-defense hypothesis for territoriality in female mammals. Ethology, Ecology and Evolution 10:227-239.

Associated editor: Jorge Servín

Submitted: December 5, 2018; Reviewed: January 19, 2019;

Accepted: January 19, 2019; Published on line: January 20, 2019. 